\title{
PENIADAAN SENIORITAS (SDM) PENGARUHNYA TERHADAP PELAYANAN JASA PERKERETAAPIAN
}

\author{
Dr. M.Guntur, MSi \\ Dosen STTD \\ Jl. Raya Setu Km. 3,5 Cibuntu, \\ Cibitung, Bekasi 17520 \\ Telp./fax. 0218254640 \\ e-mail \\ info.p3m.sttd@gmail.com
}

\author{
Widorisnomo, MT \\ Dosen STTD \\ Jl. Raya Setu Km. 3,5 Cibuntu, \\ Cibitung, Bekasi 17520 \\ Telp./fax. 0218254640 \\ Probo, ST \\ Dosen STTD \\ Jl. Raya Setu Km. 3,5 Cibuntu, \\ Cibitung, Bekasi 17520 \\ Telp./fax. 0218254640
}

\author{
Subarto, MT Dosen STTD \\ Jl. Raya Setu Km. 3,5 Cibuntu, \\ Cibitung, Bekasi 17520 \\ Telp./fax. 0218254640
}

\begin{abstract}
Vocational education is an education that leads students to develop applied skills, adaptable to particular line of work and to create job opportunities. Kepmendiknas no 232/U/2000 and Kepmendiknas no 045/U/2002, stated that: The study load 144-160 credits be taken 8-14 semester and Comparison of the core competencies (core curriculum) and supporting competencies and others (institutional curriculum) in the curriculum ranges 40-80\%: 20-40\%: 0$30 \%$.This study has the aim to determine the portion of practice and theory in the course identifier, and to know the parameters that influence performance cadets at Graduated School of Land Transport. On the subject identifier in the Program D III LLAJ has its share of 27\%, Program D III Railways has its share of 29\%, Program D IV of Land Transport has its share of $44 \%$ and Program D IV Land Transport (extension) has the share of 50\%The indicators of the practice that used as variables that affect the achievement cadets is GPA (Y), Time Spent Practice (X1), Time Spent of Writing the Report (X2), Availability of Equipment Practice (X3), Time Spent for Self study (X4) and the Duration of the Seminar / a Presentation (X5).The coefficient of determination is a percentage value for indicators of the Practice. So the Percentage Practice of analysis results is at $47.4 \%$ (52.6\% of theory) describes the condition of the attainment of Achievement Scores Cadets (GPA) tends to 3.17 (median), as normally distributed.
\end{abstract}

\section{Keywords: Vocational Education, Competencies, Course Identifier, Portion Practice and Theory, Description, Coefficient of Determination}

\begin{abstract}
ABSTRAKSI
Pendidikan vokasi merupakan pendidikan yang mengarahkan mahasiswa untuk mengembangkan keahlian terapan, beradaptasi pada bidang pekerjaan tertentu dan dapat menciptakan peluang kerja. Kepmendiknas no 232/U/2000 dan Kepmendiknas no 045/U/2002, menyatakan bahwa: Beban studi 144 - 160 sks ditempuh 8 - 14 semester dan Perbandingan kompetensi utama (kurikulum inti) dan kompetensi pendukung serta lainnya (kurikulum institusional) dalam kurikulum berkisar 40 $80 \%$ : 20-40\%: 0-30\%.Penelitian ini memiliki tujuan untuk mengetahui porsi praktek dan teori pada matakuliah penciri, dan mengetahui parameter - parameter yang mempengaruhi prestasi Taruna/i di Sekolah Tinggi Transportasi Darat. Pada matakuliah penciri pada Prodi D III LLAJ memiliki porsi $27 \%$, Prodi D III Perkeretaapian memiliki porsi $29 \%$, Prodi D IV Transportasi Darat memiliki porsi $44 \%$ dan Prodi D IV Transportasi Darat (ekstensi) memiliki porsi 50 $\%$.Indikator - indikator praktek yang dijadikan variabel yang mempengaruhi prestasi taruna adalah IPK (Y), Waktu Praktek (X1), Waktu Penyusunan Laporan (X2), Ketersediaan Alat
\end{abstract}


Praktek (X3), Waktu Belajar Mandiri (X4) dan Lama seminar/presentasi (X5).Koefisien determinasi merupakan nilai prosentase untuk indikator praktek. Sehingga prosentase Praktek dari hasil analisa adalah sebesar 47,4 \% (52,6\% teori) menggambarkan kondisi pada pencapaian nilai prestasi Taruna/i (IPK) cenderung 3,17 (median), karena terdistribusi normal.

Kata Kunci : Pendidikan Vokasi, Kompetensi, Matakuliah Penciri, Porsi Praktek dan Teori, Deskripsi, Koefisien Determinasi.

\section{PENDAHULUAN}

\section{Latar Belakang}

1. Kelembagaan dengan orientasi profit maupun non profit, senantiasa memandang manajemen SDM sebagai faktor penting dan merupakan asset. Peningkatan kualitas SDM melalui investasi mind-set menjadi prioritas, karena proses yang pada akhirnya memberikan tanggung jawab besar bagi pertumbuhan bermakna disegala sudut pengembangan SDM dimasa mendatang.

2. Kontribusi industri perkeretaapian sangat mendukung pembangunan ekonomi nasional, antara lain dapat menghemat keuangan negara karena mampu menekan kerusakan jalan raya, menghemat BBM karena mampu menekan kepadatan lalulintas di jalan raya, menurunkan biaya produksi dan harga satuan produksi konsumsi domestik karena mampu meminimalisir biaya angkutan dan distribusi.

3. Hasil survey kepuasan pelanggan yang pernah dilakukan oleh PT.KAI tahun 2014, responden memilih moda kereta api sebesar $51,44 \%$ dengan alasan kenyamanan dan karena alasan kelancaran perjalanan sebesar $22,58 \%$

4. Peran SDM sangat penting bagi pertumbuhan bisnis Perseroan karena transformasinya dimulai dari transformasi SDM.

5. Terdapat 5 alasan mengapa PT.KAI konsern membangun kerajaan bisnisnya melalui manajemen perobahan antara lain perobahan sitem renumerasi, peniadaan senioritas, sistem rekruitmen, penegakan hukum sepenuh hati, dan pengembangan SDM (trampil \& kompeten). Ke 5 alasan tersebut mendorong perobahan secara signifikan terhadap model pelayanan prima pada pelayanan jasa perkeretaapian.

6. Dengan uraian tersebut diatas, maka penulis melakukan penelitian dengan judul "PENIADAAN SENIORITAS (SDM) PENGARUHNYA TERHADAP PELAYANAN JASA PERKERETAAPIAN". 


\section{METODOLOGI PENELITIAN}

\section{Pengumpulan Data}

Metode yang digunakan adalah metode deskriptif dan metode verifikatif dengan menggunakan metode penelitian survey yaitu survey yang mengkaji keeratan hubungan variabel bebas dengan variabel terikat serta melakukan pengujian hipotesis terhadap variabel pengujian tersebut.

Selanjutnya dapat dibuatkan Paradigma Penelitian (lihat gambar ) sebagai berikut (sumber data : Diolah peneliti, 2013).

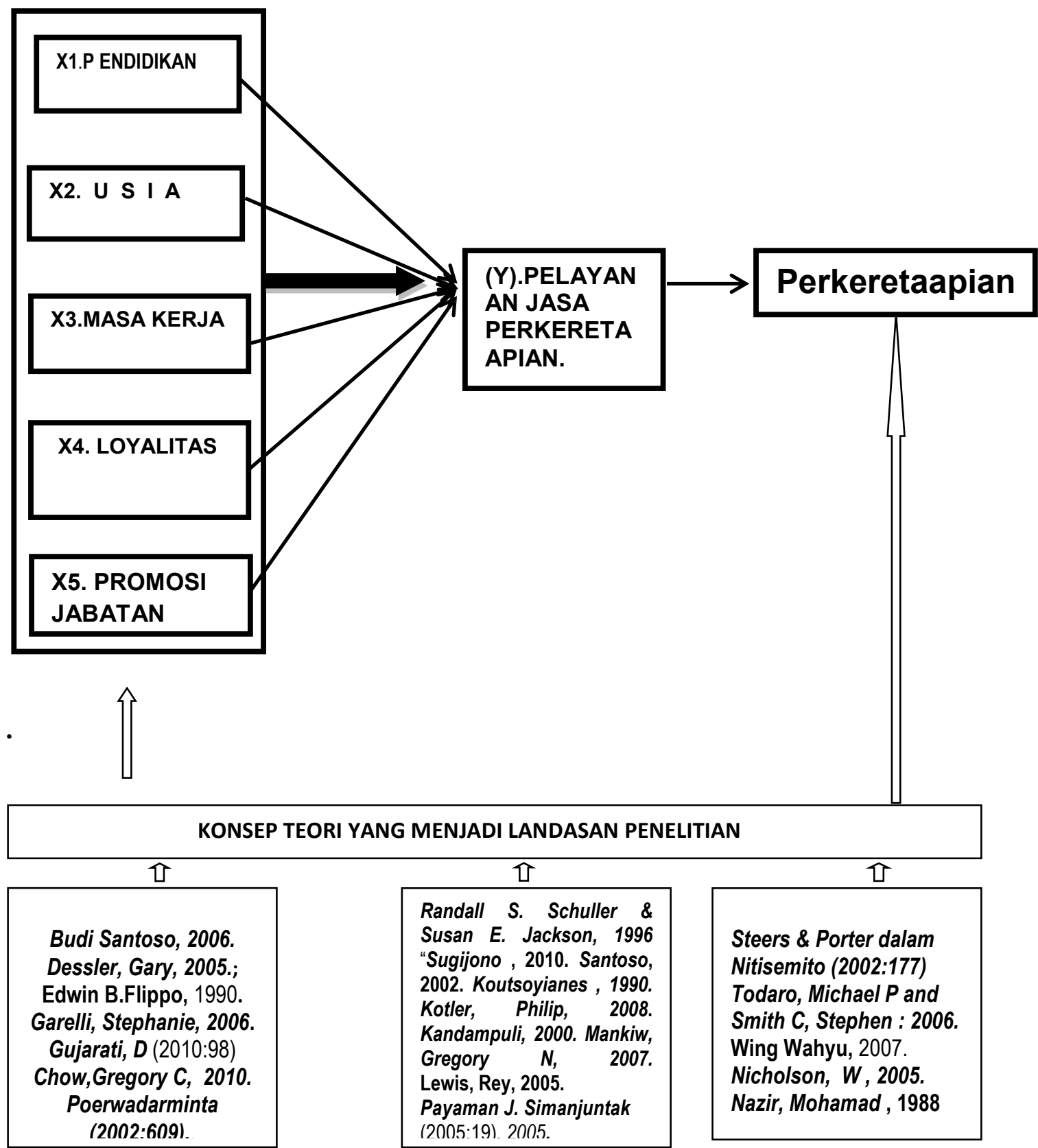

Gambar : Paradigma Penelitian 


\section{Proses Penelitian}

\section{Uji Asumsi Klasik.}

Gujarati (2003:89) menjelaskan secara rinci bahwa dilakukannya uji asumsi klasik ini adalah untuk mengetahui apakah model estimasi tersebut telah memenuhi kriteria ekonometrika, dalam pengertian bahwa tidak akan terjadi penyimpangan yang tajam dari asumsi-asumsi yang harus dipenuhi dalam 6 (enam) metode OLS (OrdinaryLeast Square) yaitu: (1) rata-rata kesalahan pengganggu (e) sama dengan nol; (2) kesalahan pengganggu berbentuk distribusi normal; (3) kesalahan pengganggu tidak berkorelasi dengan variabel independen; (4) tidak adanya autokorelasi antar gangguan (e); (5) Tidak adanya Multikolenearitas, dan (6) Varian kesalahan pengganggu tetap atau homoskedastisitas (tidak terjadi heteroskedastisitas). Apabila terjadi penyimpangan pada asumsi klasik :

Pertama, akan menyebabkan terjadinya penyimpangan dari estimasi terhadap besarnya konstanta.

Kedua, jika kesalahan pengganggu berbentuk distribusi normal tidak terpenuhi , maka tidak ada pengaruh terhadap hasil regresi dan tetap dapat diperoleh hasil estimator OLS yang BLUE ( Best Linier Unbiased Estimator).

Ketiga, secara umum hanya terjadi pada model persamaan simultan dan tidak terjadi pada model persamaan parsial (tunggal). Dengan demikian yang paling penting dalam uji asumsi klasik ini adalah menguji ada tidaknya penyimpangan asumsi: Ke empat (Uji Autokorelasi), Ke lima (Uji Multikoleniaritas) dan Keenam (Uji Hiteroskedastisitas). Selanjutnya Gujarati (2003) menjelaskannya bahwa dalam Uji BLUE (best linier unbiased estimators), asumsi-asumsi yang diuji meliputi sebagai berikut :

1) Uji Normalitas.

(1). Gujarati (2007:169), menjelaskan bahwa penggunaan analisis regresi linier telah dipersyaratkan dengan Uji Normalitas Jarque-Bera $>\boldsymbol{\alpha}=$ 0,05. Nilai Residu Model diputuskan berdistribusi normal jika peluang kesalahan (p-value) $>(\boldsymbol{\alpha}=\mathbf{0 , 0 5})$

(2). Uji Normalitas dengan Jarque -Bera (JB Test), diuji berdasarkan berdasarkan koefisien keruncingan (kurtosis) dan koefisien kemiringan (skewness). Dilakukan dengan membandingkan JB dengan $X^{2}$. Jika nilai JB $\leq$ $X^{2}$. Tabel, maka nilai residu terstandarisasi dinyatakan berdisribusi normal. Rumusnya sebagai berikut: 
$J B=n\left|\underline{S}^{2}+\underline{K-3)^{2}}\right|$

(rumus 3.1)

$6 \quad 2$

Keterangan :

$J B=$ Statistik Jarque-Bera

$K=$ Koefisien Kurtosis

$S=$ Koefisien skewness.

\section{2) Uji Multikolinearitas,}

Multikolinearitas, berarti terjadi korelasi linier yang mendekati sempurna lebih dari 2 variabel bebas. Metode yang digunakan untuk mendeteksi adanya masalah miltikolinearitas, adalah dengan melihat $\mathrm{R}^{2}$ tinggi , misalnya diatas $\mathbf{0 , 8 0 0}$ dan Uji F menolak Hipotesis Nol, tetapi t-Statistik sangat kecil. Maka gejala demikian menunjukkan adanya multikolinearitas.

Cara menentukan apakah suatu variabel bebas berhubungan secara linier dengan variabel bebas lainnya adalah dengan meregresikan setiap variabel bebas terhadap variabel bebas sisanya, dan perhatikan nilai $\mathrm{R}^{2}$, kemudian hitung nilai F-hitung dengan menggunakan rumus sebagai berikut:

\section{F-hitung $=\underline{\mathbf{R}^{2}} \mathbf{X} \underline{\text { (n-k) }}$}

$$
1-R^{2} \quad(k-1)
$$

(rumus 3.2.)

Keterangan :

$R=$ Nilai $R$ dari hasil estimasi regresiparsial variabel penjelas.

$n=$ Jumlah observasi

$k=$ Jumlah variabel penjelas (termasuk konstanta).

3) Uji Autokolerasi.

(1). Gujarati (2003) menjelaskan pula bahwa salah satu asumsi dari model regresi linier adalah bahwa tidak ada autokolerasi serial varians ( $\mathcal{E}_{\mathrm{t}}$ ), dengan penegertian lain varians menyebar bebas atau $\operatorname{Cov}(\mathcal{E} \mathrm{i}, \mathcal{E} \mathrm{j}=\mathrm{E}(\mathcal{E} \mathrm{i}, \mathcal{E} \mathrm{j})=0$ untuk semua $\mathrm{i} \neq \mathrm{j}$, dan dikenal juga sebagai bebas serial (serial independen).

(2). Melalui Uji Brausch-Godfrey Serrial Correlation Test (Wing Wahyu, 2007 :529). Apabila nilai Obs*R-Square dengan p-value $>\alpha=0,05$ berarti tidak terdapat autokorelasi pada model tersebut.

(3). Atau dengan cara lain dengan uji Durbin-Watson. adalah yang menembangkan teori Gujarati, D yang lebih populer dikenal dengan "statistik $d$ Durbin-Watson. Rumusnya sebagai berikut : 


$$
\mathrm{d}=\frac{\mathrm{n} \sum\left(\mathrm{e}_{t}-\mathrm{e}_{\mathrm{t}}-1\right)^{2}}{{ }^{n} \sum_{t=1}}
$$

Pedoman ada atau tidaknya autokorelasi dalam suatu model dapat

\begin{tabular}{|c|c|}
\hline Nilai statistik d & H a s i l \\
\hline $0<\mathrm{d}<\mathrm{dL}$ & $\begin{array}{l}\text { Menolak hipotesis nol, adanya otokorelasi } \\
\text { positif }\end{array}$ \\
\hline $\mathrm{d}_{\mathrm{L}} \leq \mathrm{d} \leq \mathrm{du}$ & Daerah keragu-raguan tidak ada keputusan \\
\hline $\mathrm{du} \leq \mathrm{d} \leq 4-\mathrm{du}$ & $\begin{array}{c}\text { Menerima hipotesis nol,tidak ada otokorelasi } \\
\text { positif atau negatif }\end{array}$ \\
\hline $4 \mathrm{du} \leq \mathrm{d} \leq 4 \mathrm{~d}_{\mathrm{L}}$ & Daerah keragu-raguan tidak ada keputusan \\
\hline $4 \mathrm{~d}_{\mathrm{L}} \leq \mathrm{d} \leq 4$ & $\begin{array}{c}\text { Menerima hipotesis nol,tidak ada otokorelasi } \\
\text { negatif }\end{array}$ \\
\hline
\end{tabular}
diperhatikan tabel berikut ini :

Tabel 3.1 Uji statistik Durbin Watson

\section{4) Uji Hiteroskedastisitas}

(1). Gujarati (2003) menjelaskan bahwa jika varians tidak sama atau $\operatorname{Var}(\varepsilon \mathrm{i})=\mathrm{E}\left(\mathcal{E} \mathrm{i}^{2}\right)=\sigma \mathrm{i}^{2}$, untuk tiap pengamatan ke- $i$ dari variabel bebas dalam model regresi maka kita katakan ada masalah hiteroskedastisitas. Masalah hiteroskedastisitas sering terjadi pada data time series maupun data cross section.

(2) Metode White, dilakukan dengan meregresikan semua variabel bebas terhadap nilai residual kwadratnya. Jika nilai $\mathrm{X}^{2}$-hitung > nilai $\mathrm{X}^{2}$ tabel dengan df $=n-k-1$, pada $\alpha=0,05(k=$ jumlah variabel bebas, $n=$ jumlah observasi) maka model terdapat masalah heteroskedastisitas. Nilai $\mathrm{X}^{2}$ hitung dalam metode ini diperoleh $n \times R^{2}$, dimana $n=$ jumlah observasi, sedangkan $\mathrm{R}^{2}$ adalah koefisien determinasi regresi tahap kedua. Jika model regresi yang akan diuji memiliki dua variabel bebas yaitu X1 dan X2, maka persamaan yang digunakan untuk uji heteroskedastisitas metode white adalah sebagai berikut :

$$
\mathcal{E} i=\beta 0+{ }_{\beta 1 X 1}+\beta 2 X 2+\beta 3 X 1^{2}+\beta 4 X 2^{2}+\beta 5 X 1 X 2+\mathcal{E} \text {. }
$$

Keterangan :

$\mathcal{E} \mathbf{i}=$ Nilai residual

$\mathrm{X} 1=$ variabel bebas. 
Dengan program Eviews maka akan di dapat, apabila nilai observasi R-square pada hasil tersebut dan nilai probabilitasnya $<\alpha=0,05$, maka disimpulkan bahwa data tersebut bersifat hiteroskedastisitas

\section{Hipotesis Statistik.}

\section{a. Uji Statistik F ( Uji Hipotesis Simultan)}

Dipergunakan untuk menguji nyata tidaknya pengaruh (X1), (X2), (X3), SDM (X4), (X5) secara simultan/serempak terhadap (Y).

Ketentuan Pengujian: Dengan menggunakan derajat kepercayaan $5 \%$ atau apabila alpha $(\alpha) 5 \%$, maka F-tabel $=\mathrm{F}_{0,05} ;(\mathrm{k} ; \mathrm{n}-\mathrm{k}-1)$.

\section{b. Uji t (uji hipotesis parsial).}

Dipergunakan untuk menguji nyata tidaknya pengaruh (X1), Kapal (X2), Tunjangan (X3), (X4), (X5) secara parsial terhadap (Y).

Ketentuan pengujian : Dengan alpha $5 \%$ maka t-tabel $=\mathrm{t}_{0}, 05 ;(\mathrm{n}-\mathrm{k}-1) \mathrm{k}=$ jumlah varians $\mathrm{H}_{0}$ diterima apabila t-hitung $\leq \mathrm{t}$-tabel; $\mathrm{H}_{0}$ ditolak apabila t-hit > t-tabel.

\section{Koefisien Determinasi $\left(R^{2}\right)$.}

Koefisien Determinasi atau Koefisien Penentu (KP) digunakan untuk mengetahui seberapa besar kontribusi pengaruh $\mathrm{X}$ terhadap $\mathrm{Y}$ dan bermanfaat untuk mengukur seberapa jauh kemampuan model dalam menerangkan variasi variabel terikat.

\section{Pengujian Kelayakan Model.}

Koutsoyiannes (1977:29-30) dan Yuyun Wirasasmita (2008: 124), mengatakan bahwa syarat hasil uji kelayakan model menunjukkan bahwa model penelitian telah memenuhi the goodness of an econometric model (karakteristik yang dapat diharapkan), yakni

a. Theoretical Plausibility, yakni model penelitian yang memperlihatkan apakah hasil uji telah sesuai dengan ekspektasinya dari teori ekonomi yang menjadi dasar pemikirannya.

b. Accuracy of the estimatelof the parameters, yakni model penelitian yakni model penelitian memperlihatkan apakah hasil uji telah sesuai dengan ekspektasinyadari teor ekonomi menjadi dasar pemikirannya.telah menghasilkan estimator koefisien regresi yang akurat, tidak bias dan signifikan. Terdapat probabilitas ( $\mathrm{p}$-value) kesalahan statistik dari model sangat rendah $(\mathrm{p}$-value $=0,00)$ atau lebih kecil dari $\alpha$ $(0,05)$. 
c. Explanatory ability, yakni model penelitian memiliki kemampuan yang tinggi dalam menjelaskan fenomena ekonomi yang menjadi kajian. SE (standard error of estimates), dimana varriance error of estimates $=\mathrm{SE}^{2}<$ mean square of regression dalam tabel Anova.

d. Forecasting ability, yakni model penelitian akan memiliki kemampuan prediksi yang tinggi atas perilaku variabel terikat, kriterianya jika tingginya koefisien determinasi model mendekati atau melebihi $50 \%$.

Tabel 3.2 Rancangan Uji Kesesuaian teori

\begin{tabular}{|l|c|c|c|}
\hline \multicolumn{1}{|c|}{ Hubungan Antar Variabel } & $\begin{array}{c}\text { Pra- } \\
\text { Estimasi }\end{array}$ & $\begin{array}{c}\text { Pasca- } \\
\text { Estimasi }\end{array}$ & $\begin{array}{c}\text { Kesesuai } \\
\text { an }\end{array}$ \\
\hline Pengaruh Parsial X1 terhadap Y & + & & \\
\hline Pengaruh Parsial X2 terhadap Y & + & & \\
\hline Pengaruh Parsial X3 terhadap Y & + & & \\
\hline Pengaruh Parsial X4 terhadap Y & + & & \\
\hline Pengaruh Parsial X5 terhadap Y & + & & \\
\hline $\begin{array}{l}\text { Pengaruh Simultan Variabel X terhadap } \\
\text { Y }\end{array}$ & + & & \\
\hline
\end{tabular}

Sumber : Diolah peneliti (2015)

\section{KESIMPULAN DAN SARAN}

\section{A. KESIMPULAN}

1. Secara simultan variabel X1., X2., X3., X4. dan X5. berpengaruh signifikan terhadap variabel Y. Pada prinsipnya Senioritas ( Pendidikan, Usia dan Masa Kerja) akan efektif jika pemangku senioritas unggul dalam program investasi mind-set yang memberi peluang bagi masing-masing SDM yang outputnya dapat meningkatkan kinerja individu sebagai unsur penilaian promosi jabatan dampaknya terhadap pelayanan jasa perkeretaapian. Dengan demikian peniadaan senioritas bersifat temporer dan situasional.

2. Secara parsial variabel (X1) (X2) (X3) (X4) dan (X5) berpengaruh positif dan signifikan terhadap variabel $\mathrm{Y}$. Manajemen harus menghargai atas kinerja yang dicapai, dikarenakan masing-masing SDM telah memenuhi kriteria. 
3. Besarnya angka $R$ square $\left(\mathrm{R}^{2}\right)$ adalah 0.980788. Angka tersebut mempunyai maksud bahwa sumbangan pengaruh variabel (X) terhadap variabel (Y) adalah $98.07 \%$, sedangkan sisanya sebesar 1,93\% dipengaruhi oleh faktor lain.

4. Model penelitian menghasilkan mayoritas arah pengaruh yang sesuai ekspektasinya dari teori perobahan struktural (theoretical plausibility) yang merupakan dasarnya yaitu:

a. Menghasilkan estimator koefisien yang seluruhnya signifikan (accuracy of the estimates parametters).

b. Dinilai memiliki kemampuan tinggi dalam menjelaskan kelayakan model penelitian (explanatory ability).

c. Memiliki kemampuan prediksi yang tinggi (forecasting ability) atas variabel yang dikaji sebagaimana koefisien determinasi (pengaruh total) model yang melebihi 50\% $\left(\mathrm{R}^{2}=98.07 \%\right)$.

d. Koefisien determinasi merupakan ukuran kecocokan hasil estimasi sebuah model regresi linier dengan data yang dimodelkan (goodness of fit) dari sebuah model regresi linier.

\section{B. SARAN}

1. Apabila Faktor-Faktor Senioritas akan digunakan sebagai acuan dalam rangka Promosi Jabatan, maka faktor Loyalitas tidak boleh diabaikan karena justru loyalitas akan memberikan nilai kredit positif bagi setiap pengambil kebijakan. Kepercayaan lebih bagi loyalis adalah nilai non finansial sebagai penghargaan atas prestasinya dalam pelayanan jasa perkeretapian.

2. Masing-masing variabel (sub-sistem) memiliki keterikatan yang berkorelasi positif terhadap sistem pelayanan jasa perkeretaapian. Manajemen harus berproses dalam menuju semangat dalam peran di masing-masing variabelvariabel tersebut.

3. Sumbangan angka pengaruh variabel $(\mathrm{X})$ terhadap variabel $(\mathrm{Y})$ adalah $98.07 \%$, sedangkan sisanya sebesar 1,93\% dipengaruhi oleh faktor lain. Manajemen hendaknya dapat melakukan trobosan peluang bisnis baru seperti halnya pengembangan multimoda dan pembangunan Container Yard pada area Stasiun KA dalam mempertahankan Pelayanan Jasa Prima dilingkungan perkeretaapian.

4. Estimasi dan prediksi pengembangan bisnis dimasa mendatang yang diprioritaskan adalah investasi mind-set bagi seluruh jajaran SDM perkeretaapian. Hal ini dilakukan karena PT.KAI harus melahirkan konsep 
pengembangan produksi jasa perkeretaapian dengan misi penyediaan peluang kerja dan meningkatkan kesejahteraan masyarakat.

\section{DAFTAR PUSTAKA}

1. -----------, (2000), Keputusan Menteri Pendidikan Nasional Nomor 232/U/2000 tentang Pedoman Penyusunan Kurikulum Pendidikan Tinggi dan Penilaian Hasil Belajar Mahasiswa.

2. ----------, (2002), Keputusan Menteri Pendidikan Nasional Nomor 045/U/2002 tentang Kurikulum Inti Pendidikan Tinggi.

3. ---------, (2003), Undang - Undang Nomor 20 Tahun 2003 tenteng Sistem Pendidikan Nasional.

4. Budi Santoso, 2006. "Bank dan Lembaga Keuangan lainnya” edisi 2 Jakarta" (Penerbit Gramedia Pustaka Utama Jakarta).

5. Dessler, Gary, 2005. Manajemen SDM (PT.Prenhallindo Jakarta)

6. Edwin B.Flippo, 1990 "Personnel Management, Sixth Edition

7. (Mc.Graww.Hill.Inc).

8. Garelli, Stephanie, 2006. Top Class Competitors, How Nations, Firms an IndividualsSucceed in The New Word of Competitiveness (PT.Gramedia Jakarta).

9. Gujarati, D (2010:98) Dasar-Dasar Ekonometrika (Penerbit PT. Grafika Pustaka Jakarta).

10. Chow,Gregory C, 2010. “Interpreting China's Economy” ( Word Scientific Publishing Co.Pte.Ltd Singapore).

11. Poerwadarminta (2002:609),. Kamus Bahasa Indinesia (PT. Bina Ilmu Bandung).

12. Randall S. Schuller \& Susan E. Jackson, 1996 “ Human Resources Management” positioning for the 21st Century/6th.ed (by Erlangga Copyright).

13. Sugijono , 2010. Metode Penelitian Kuantitatif dan Kualitatif dan R \& D (Penerbit Alfabeta Jakarta).

14. Santoso, 2002. Statistik Parametrik (Penerbit Gramedia Pustaka Cetakan Ketiga).

15. Koutsoyianes, 1990. Theory of Econometric : An Introductory Expsition Econometric Methods. (The Mc.Milann Press Ltd, United Kongdom)

16. Kotler, Philip, 2008. Marketting Management Ed.11 Engelwood Cliffs Prentice Hall International Edition, New Jersey.

17. Kandampuli, 2000. Kualitas Pelayanan Publik (Penerbit Mutiara Bandung).

18. Lewis, Rey, 2005. "Questionnaires and Inventories : Surveying Openions \& Assessing Personality” (New York McGraw Hill Co). 
19. Mankiw, Gregory N, 2007. Macro Economics, The Sixth Edition" ( Harvard University By Worth Publishers).

20. Mulyasa, 2007. Menjadi Guru Profesional (Remaja Rosdakarya Bandung).

21. Nazir, Mohamad, 1988. Metode Penelitian (penerbit Ghalia Indonesia).

22. Nitisemito ,2002:134)

23. Nicholson, W , 2005. Microeconomic Theory: Basin Principles and Extentions (Ninth Edition Word.Press.Com).

24. Payaman J. Simanjuntak (2005:19), 2005. “Manajemen \& Evaluasi Kinerja" (Gramedia Utama Jakarta)

25. Sukirno,Sadono 2011. Makro Ekonomi, Teori dan Pengantar (Rajagrafindo Persada, Edisi Ketiga Jakarta).

26. Siswanto (dalam Nitisemito, 2002:167).

27. S. Notoatmodjo, 2011 “Pengembangan SDM “(penerbit Rineka Cipta jakarta)

28. Steers \& Porter dalam Nitisemito (2002:177)

29. Todaro, Michael P and Smith C, Stephen : 2006. Economics for a developing World (Erlangga Jakarta).

30. Wing Wahyu, 2007. Analisis Ekonometrika dan Statistik dengan Eviews. (Yogyakarta 2007) 